\title{
EDGE DETECTION TECHNIQUE ON OBJECTS PRESENT IN HIGH RESOLUTION OPTICAL SATELLITE IMAGES
}

\author{
WILVER AUCCAHUASI ${ }^{1}$, CHRISTIAN OVALLE ${ }^{1}$, EDWARD FLORES $^{1}$, FERNANDO SERNAQUÉ $^{2}$, \\ EDWIN FELIX ${ }^{2}$, MARIO RUIZ ${ }^{2}$, JAVIER FLORES ${ }^{2}$, GLORIA ROJAS ${ }^{3}$ \\ ${ }^{1}$ Universidad Privada del Norte, Lima, Perú \\ ${ }^{2}$ Instituto Peruano de Investigación en Ingeniería Avanzada, Lima, Perú \\ ${ }^{3}$ Servicio Nacional de Aprendizaje SENA-Region Caldas, Manizales, Colombia
}

\begin{abstract}
Satellite images provide information on land cover, these will depend on the spatial resolution for analysis, in this paper we present a technique for image analysis based on edge detection using sobel-based detectors, in their different shapes. High-resolution satellite images provide a level of detail of land cover in the submetric range, which is equivalent to detecting objects that measure less than 1 meter on average, which is interpreted in one pixel in the image; With the analysis of high resolution images, objects such as ships can be determined, which are found in ports as well as on the high seas. Edge detectors applied to objects present in high resolution images help in the analysis of the morphology of the object. In the present study, high resolution images corresponding to boats were analyzed, which allows determining the contour of the boat with respect to sea water. The application of sobel-based edge detectors and their different shapes allowed determining a greater number of areas that corresponds to the perimeter of the ship. The results of the present work can be used in pattern recognition techniques to determine the characteristics of the objects to be analyzed.
\end{abstract}

KEYWORDS: Sobel, Borders, Satellite Image, Pixel, Convolution

Received: Jun 08, 2020; Accepted: Jun 28, 2020; Published: Sep 14, 2020; Paper Id.: IJMPERDJUN20201223

\section{INTRODUCTION}

The use of high-resolution satellite images are being used more frequently, thanks to the different satellites that provide this important information on land cover, among the most important uses are the analysis of the coverage of vegetation areas that cover Much of the land cover, the analysis of these images can be used through the use of artificial intelligence techniques [1]. High resolution images also provide information in the visible color bands and these can also be used as mechanisms to identify other characteristics, in very particular uses such as vegetation. [2 ] [6]. Another modality of satellite images available today is radar images, which provide information on land cover based on the analysis of texture characteristics [3]. Satellite images, in any of their modalities, provide information on large areas of land, therefore the size and weight is very high in most cases their processing requires specialized hardware to process the images. [4] [5].

\section{METHODS \& MATERIALS}

The processing of satellite images is one of the challenges today, both due to the complexity of its formation and the complexity of the image itself. The present study will analyze the gray scale images. They can be formed in two ways: 
- Through the original image extracted from the panchromatic band.

- Through the process of converting a color image into a grayscale image, using any type of processing or criteria.

The fundamental part of the proposed methodology is to be able to work with a gray scale image, which can be obtained with any of the three modalities described above.

The analysis of the images using the sobel edge detectors in their $\mathrm{X}$ gradient and $\mathrm{Y}$ gradient forms, this analysis is carried out individually, to analyze the results independently. This analysis is performed thanks to the image convolution process.

After obtaining the images with the corresponding edges, the best image with the edges that best represents the original image is chosen, where the details of the edges present in the high resolution satellite images can be discriminated.

Below is a flow chart where the sequence of steps to be taken to explain the methodology is identified.

\section{Blocks Diagram}

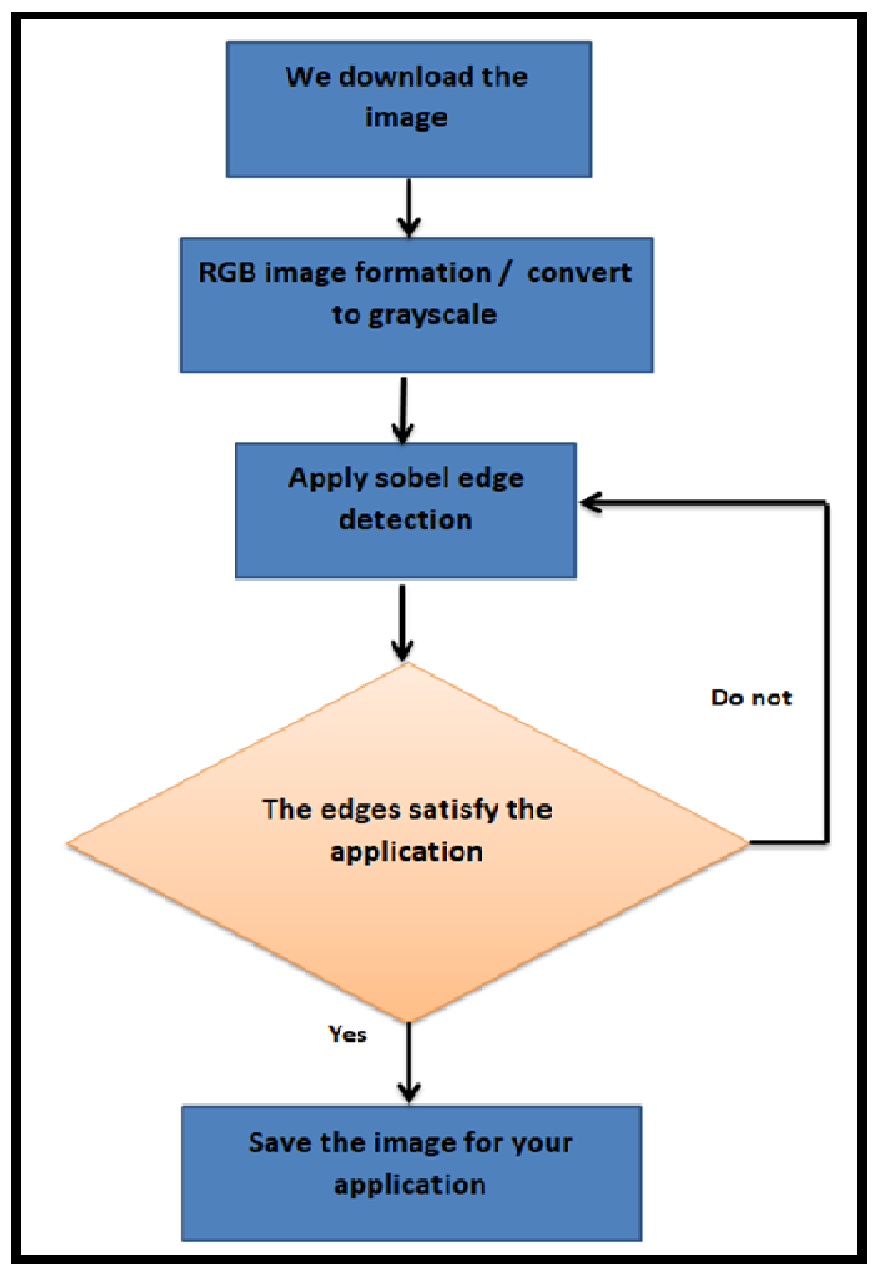

Figure 1: Block Diagram of the Proposal.

In figure 1, the description of the proposed methodology is presented, which is based on the processes on edge detection according to the sobel mask. 
In the analysis of the different types of images, the image convolution technique is used, applying the different edge detection matrices, mainly Sobel's edge detectors with their different variants; the value of the white pixels in the image belong to the edges found in the image.

In order to consider in the proposal, we can indicate that an image as a two-dimensional arrangement denoted by $\mathrm{X}(\mathrm{i}, \mathrm{j})$ and a filter better known as kernel or convolution mask, with impulsive response $\mathrm{h}(\mathrm{i}, \mathrm{j})$. The convolution process produces an output image y (i,j), according to the following image 2 .

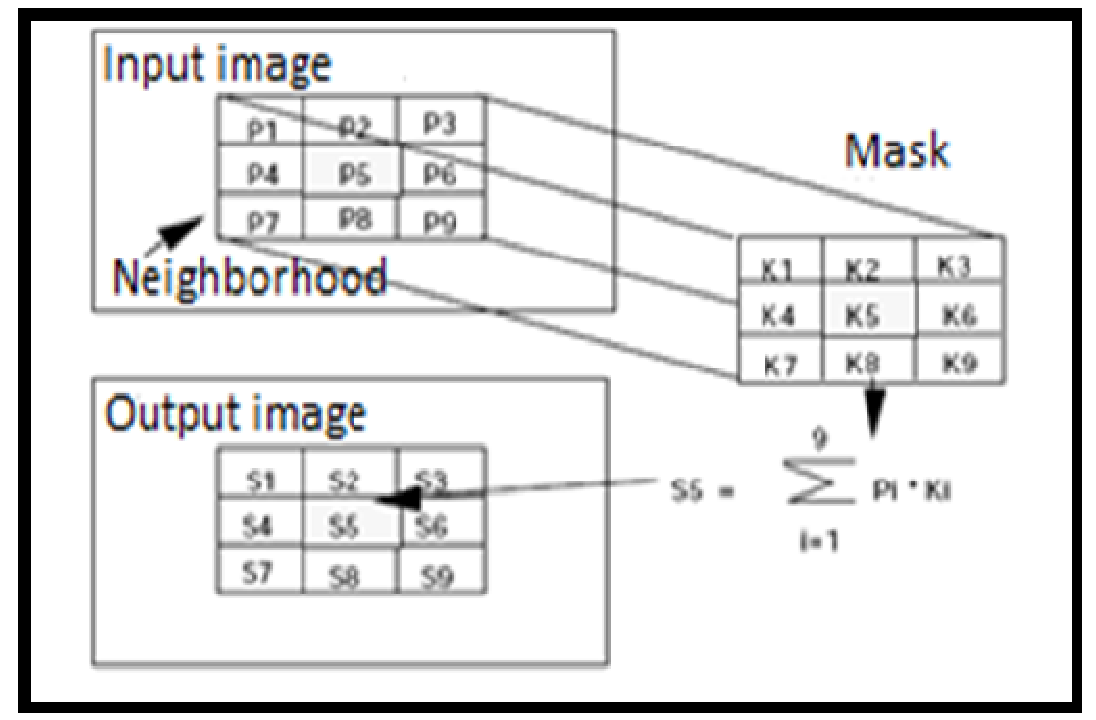

Figure 2: Image Convolution Process.

The convolution mask usually has an odd number of rows and columns and its size is often $3 \mathrm{X} 3$, its content depends on the type of processing you want to implement.

The sobel masks that will be used are the $\mathrm{X}$ gradients and the $\mathrm{Y}$ gradients, in both cases $3 \mathrm{X} 3$ masks will be used, as described below:

\begin{tabular}{|c|c|c|}
\hline-1 & -2 & -1 \\
\hline 0 & 0 & 0 \\
\hline 1 & 2 & 1 \\
\hline
\end{tabular}

Figure 3: Gradient Sobel Mask Y.

\begin{tabular}{|c|c|c|}
\hline-1 & 0 & 1 \\
\hline-2 & 0 & 2 \\
\hline-1 & 0 & 1 \\
\hline
\end{tabular}

Figure 4: Gradient Sobel Mask X. 
High-resolution satellite imagery provides detailed information on objects found in land cover; Below are three images that correspond to ships that are on the high seas, on which the sobel masks will be applied in order to obtain their edges.

\section{Detecting Edges in Satellite Images}

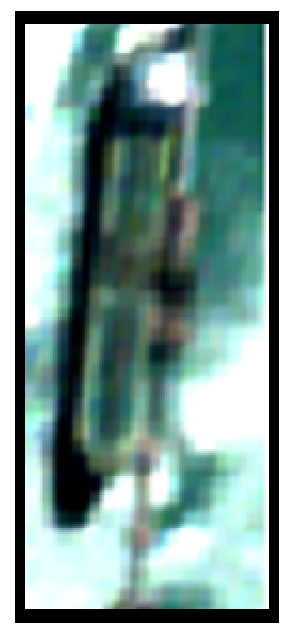

Figure 5: First Image to Evaluate.

In image 5, the image of a ship on the high seas is observed, the level of detail of the image is poor, and it is a characteristic of satellite images, when trying to observe the content of the image with a higher level of detail satellite. The background of the image is presented brilliantly by the reflection of sunlight in the sea, this will be one of the main problems when detecting the edges.

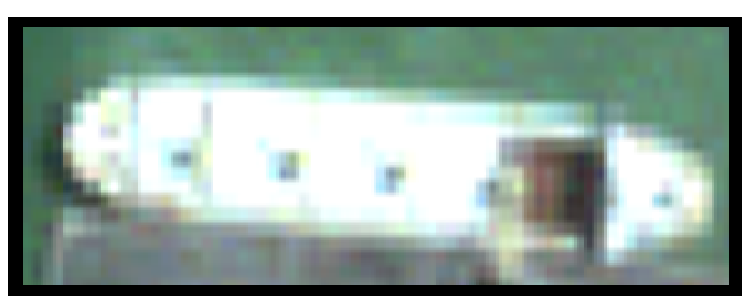

Figure 6: Second Image to Evaluate.

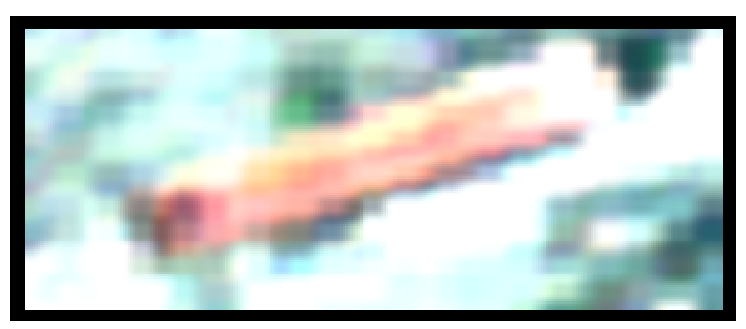

Figure 7: Third Image to Evaluate.

In image 6, a ship is presented on the high seas, unlike the image in figure 5, it does not show the reflection of light in the waters of the sea. 
In figure 7 , the image of the ship is presented, but the sea has a lot of reflection making it difficult to detect the edges.

Figures 5, 6 and 7 represent ships, these images have been cut from a satellite image in the RGB color scheme, the three images correspond to different areas on the high seas, so the backgrounds are different, which corresponds to images of water, one of the characteristics of satellite images, is that if we increase the size of the image, the image presents deformation characterized by the pixelation.

\section{RESULTS}

The image processing has been carried out independently, in which the two edge detectors were applied to each of them, the following images show the processes carried out and the results obtained:

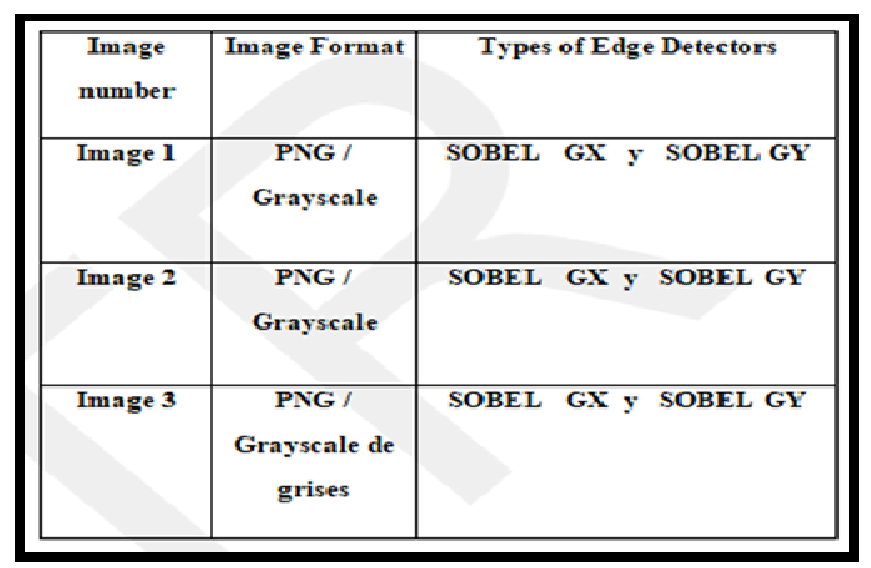

Figure 8: Description of the Images to be Evaluated.

\begin{tabular}{|c|c|c|c|}
\hline Image number & Image Format & $\begin{array}{c}\text { Types of edge } \\
\text { detectors }\end{array}$ & $\begin{array}{c}\text { Algorithm } \\
\text { effectiveness } \\
\text { percentage }\end{array}$ \\
\hline Image 1 & $\begin{array}{c}\text { PNG / } \\
\text { Grayscale }\end{array}$ & SOBEL GY & $80 \%$ \\
\hline Image 2 & $\begin{array}{c}\text { PNG/ } \\
\text { Grayscale }\end{array}$ & SOBEL GX & $81 \%$ \\
\hline Image 3 & $\begin{array}{c}\text { PNG / } \\
\text { Grayscale de } \\
\text { grises }\end{array}$ & SOBEL GX & $80 \%$ \\
& & & \\
&
\end{tabular}

Figure 9: Results of Applying Edge Detectors.

Figure 8 shows the detail of the images to be analyzed, with their respective convolution mask, and image 9 shows the result of applying the edge detectors for the gradient in $\mathrm{X}$ and the gradient in $\mathrm{Y}$, with their respective degrees of effectiveness indicating the percentage of edges found, with this analysis you can choose the best option to use edge detectors. 


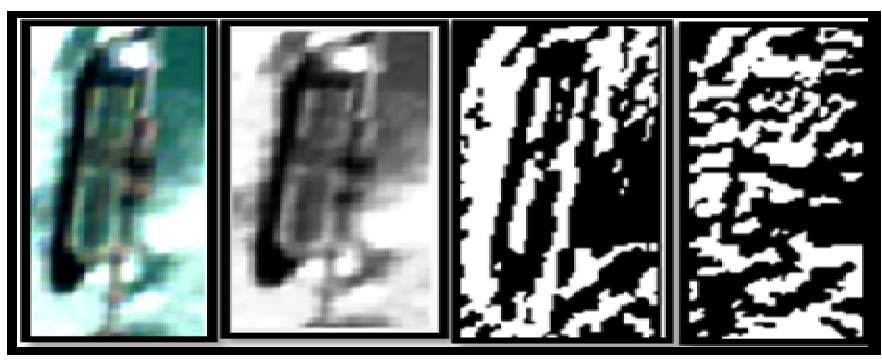

Figure 10: Results of the First Image.

Image 10 shows the results of the first image of the ship, where the four processing stages are, first the original image, second the grayscale image, third the image with GY sobel and fourth the image with GX sobel, in this particular case the result that best demonstrates the edges is with the use of GY sobel, in the case of GX sobel the resulting image does not indicate the edges of the boat image.

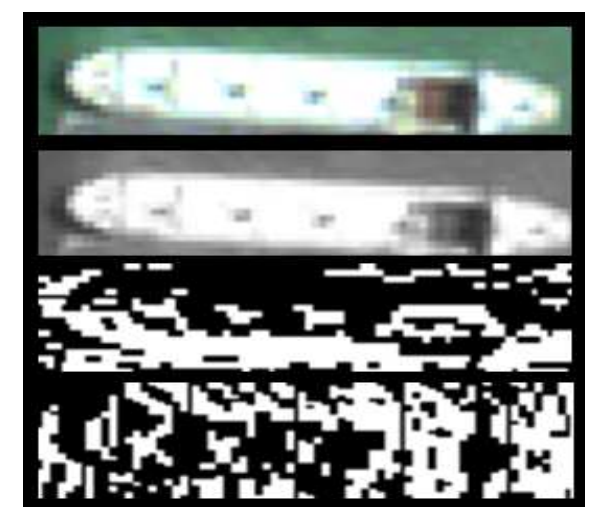

Figure 11: Results of the Second Image.

In image 11, the result of processing the second image is presented, in this particular case the best result is processing the image with GX sobel, compared to the GY sobel image.

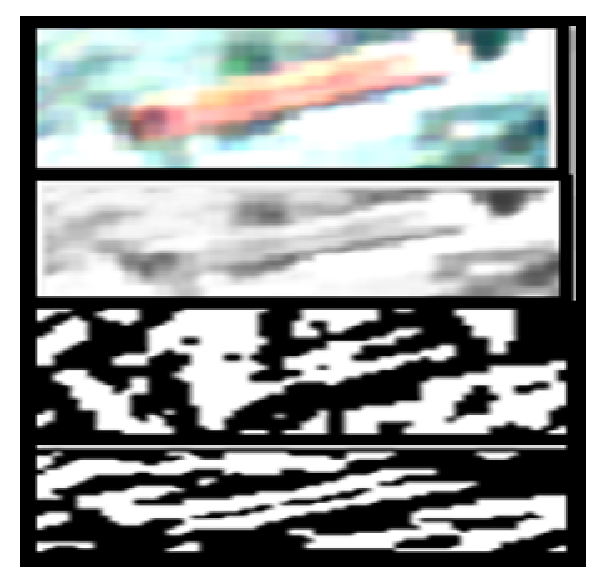

Figure 12: Results of the Third Image.

Image 12 shows the result of processing the third image, where the best result presents the image with GX sobel processing. 


\section{CONCLUSIONS}

Analyzing satellite images provide a degree of complexity both in the handling and in the interpretation of the objects that are present in the images. High-resolution images make it possible to distinguish objects on a high scale from other forms of satellite imagery.

With the result obtained in the present investigation, it can be identified that the edge detectors allow analyzing in more detail the characteristics of the object, both for obtaining the characteristics of shape, dimensions, which indicates the importance of its application.

In the image analysis techniques, both to be used and inputs for use by artificial intelligence, edge detection is one of the necessary and widely used processes, therefore its importance of use, the method presented allows the detector to be used de sobel simultaneously in its two variants, instead of using it separately.

When analyzing the images of the ships, the variant of sobel will depend on the orientation of the ship in the image, as can be seen in the results of the processed images. For future work, it is advisable to analyze the image background in better detail because it presents abundant noise in the final image result.

\section{REFERENCES}

1. Wilver Auccahuasi, Jorge Del Carpio, Raul Benites, Karin Rojas, Edward Flores, Elizabeth Oré. (2020). Classification of Vegetable Coverage Through Chromatic and Technical Characteristics of Artificial Intelligence Using Satellite Images. International Journal of Advanced Science and Technology, 29(3), 7509 - 7513. Retrieved from http://sersc.org/journals/index.php/IJAST/article/view/7987

2. Wilver Auccahuasi, Madelaine Bernardo, Elizabeth Oré Núñez, Fernando Sernaque, Percy Castro, and Luis Raymundo. 2018. Analysis of Chromatic Characteristics, in Satellite Images for the Classification of Vegetation Covers and Deforested Areas. In Proceedings of the 2018 the 2nd International Conference on Video and Image Processing (ICVIP 2018). Association for Computing Machinery, New York, NY, USA, 134-139. DOI:https://doi.org/10.1145/3301506.3301550

3. Wilver Auccahuasi Aiquipa, Fernando Sernaque, Orlando Aiquipa, Edward Flores, Monica Diaz, and Elizabeth Oré Núñez. 2019. Analysis of Images in the Discrimination of Land Cover, by Processing Radar Satellite Images. In Proceedings of the 2019 2nd International Conference on Sensors, Signal and Image Processing (SSIP 2019). Association for Computing Machinery, New York, NY, USA, 58-61. DOI:https://doi.org/10.1145/3365245.3365254

4. Wilver Auccahuasi Aiquipa, Jorge del Carpio, Jorge Garcia, Raul Benites, Juan Grados, and Edward Flores. 2019. Analysis of High Resolution Panchromatic Satellite Images, Based on GPGPU Programming. In Proceedings of the 2019 2nd International Conference on Sensors, Signal and Image Processing (SSIP 2019). Association for Computing Machinery, New York, NY, USA, 45-48. DOI:https://doi.org/10.1145/3365245.3365253

5. Auccahuasi, W., Castro, P., Flores, E., Sernaque, F., Garzon, A., \& Oré, E. (2020). Processing of fused optical satellite images through parallel processing techniques in multi GPU. Procedia Computer Science, 167, 2545-2553.

6. Auccahuasi, W., Sernaque, F., Flores, E., Garzon, A., Barrutia, A., \& Oré, E. (2020). Analysis of the chromatic characteristics, on land cover types using synthetic aperture images. Procedia Computer Science, 167, 2524-2533. 
